\title{
Chorioangioma: A Case Report
}

\author{
Veena Panat ${ }^{1}$ (1)
}

Received: 18 November 2019/Accepted: 31 August 2020/Published online: 31 October 2020

(C) The Author(s) 2020

\begin{abstract}
Chorioangiomas are benign tumors of the placenta, characterised by AV shunting within placenta leading to fetal anemia, cardiomegaly and hydrops. Maternal complications are also known as polyhydramnios, APH and Mirror syndrome. They are seen after 20 weeks, and most of them remain small and are asymptomatic. Large ones $(>4 \mathrm{~cm})$ can create complications for the fetus and expectant mothers. The proximity of the chorioangioma to the placental cord insertion site and its size determines prognosis. Prenatal therapy in the form of interventions like direct injections of various chemicals and laser coagulation of the tumor's feeding vessels are described in the literature. Conservative management may also be offered in certain circumstances. We report a case of large Chorioangioma managed conservatively. Early diagnosis was made, patient counseling followed by close surveillance with Doppler, MCA PSV was done for fetal wellbeing. The timely intervention led to good neonatal and maternal outcome aided with NICU management.
\end{abstract}

Keywords Chorioangioma $\cdot$ Hydrops $\cdot$ Placenta

\section{Introduction}

Chorioangiomas are the most common benign tumors of the placenta and have an incidence of $0.2-0.6 \%$. Some authors have quoted an incidence of around $1 \%$ [1]. It was first described by Clarke in the year 1978 [2]. With the advent of color Doppler, these can be easily detected

Veena Panat

veenamoghepanat@gmail.com

1 Panat Hospital, Aurangabad, India antenatally [2]. On ultrasound, they appear as a well circumscribed, rounded, predominantly hypoechoic lesion near the chorionic surface, protruding into the amniotic cavity [1.]. Because of the resemblance of the tumor's components to the blood vessels and stroma of the chorionic villi, the term Chorioangioma has been considered appropriate.

These benign tumors are discrete masses composed of multiple fetal capillaries supported by stroma and are predominantly perfused by fetal circulation. Chorioangioma size and vascularity correlate with the volume of fetal blood shunted to the mass and is of prognostic importance to fetal outcome [3].

Small masses are asymptomatic. Larger tumors (> $4 \mathrm{~cm}$ ) may be associated with significant arteriovenous shunting within the placenta and lead to fetal anemia, cardiac failure and hydrops. Platelet sequestration and erythrocyte damage within the mass can also cause fetal microangiopathic anemia and thrombocytopenia. Significant polyhydramnios may develop and theories for this occurence include transudate from tumor vessels across the chorionic plate and the increased fetal urine output with a hyperdynamic cardiac state [3].

Antepartum hemorrhage, preterm delivery, polyhydramnios and fetal growth restriction may complicate large tumors. Some chorioangiomas may not be identified by routine prenatal ultrasound. Even in the absence of ultrasound abnormalities, neonatal morbidity as measured by NICU admission rate is increased [4]. Because of severe fetal sequelae and poor perinatal outcome with large tumors, treatment may include an attempt to reduce blood flow to the tumor by means of vessel occlusion or ablation $[1,3,5]$. Amnioreduction may also give temporary relief [3]. Conservative management in controlled settings with a frequent checkup, ultrasound and Doppler may also give 
good results. Percutaneous treatment options are ideal for the reduction of maternal and fetal morbidity.

Ultrasound guided percutaneous treatment options include alcohol injection, embolization and interstitial therapy [6]. In our case, even though our team had the experience of intervention and uterine artery embolization for $\mathrm{PPH}$, for want of experience of embolization in chorioangiomas, we did not offer it to the patient.

Counseling of the patients and relatives was done after diagnosis. The plan of conservative management was explained to the patient and her family and their verbal consent was taken. The inherent fetal and maternal risks due to chorioangioma were explained to them.

\section{Case Report}

A young, primi, literate patient, from a good socioeconomic background, came with 7-8 weeks amenorrhoea. They were in a non-consanguineous marriage. Pregnancy was confirmed and folate supplementation started. Ultrasound confirmed 7-8 weeks viable pregnancy after which blood investigations were carried out, and found normal. At 12 weeks, an NT scan was performed, which was entirely normal. Placenta was reported to be placed anteriorly, upper segment.

An anomalies scan done at another center at 20-21 weeks gestation showed a single fetus with no obvious anomaly; the placenta was placed anteriorly with well defined circumscribed hypoechoic lesion towards the amniotic surface. Active blood flow was not seen. The tumor was seen arising near the cord insertion site and features were suggestive of a chorioangioma $(20 \times 30 \times 20$ $\mathrm{mm})$. When the patient came to show the reports, references about chorioangioma were read out to her along with her husband, (increased surveillance advised by all references). Counseling was done, being healthcare professionals themselves, they had many queries which were answered patiently. Possible maternal and fetal complications were explained.

At 26 weeks, the patient came again for a routine followup. Her general and abdominal exam was normal, with fetal cardiac activity auscultated.

Ultrasound showed an increase in size to $60 \times 50 \times 50$ $\mathrm{mm}$ with normal blood flow as shown in Figs. 1, 2. Fetal interval growth was normal. The patient was advised to come for a follow up after 2-3 weeks.

At 32-34 weeks, when the patient came for a follow up, her general condition was good, but she had complaints of decreased fetal movement. Ultrasound showed significant increase in the size of the chorioangioma to $80 \times 90 \times 80$ $\mathrm{mm}$ with increased vascularity and turgid vessels and

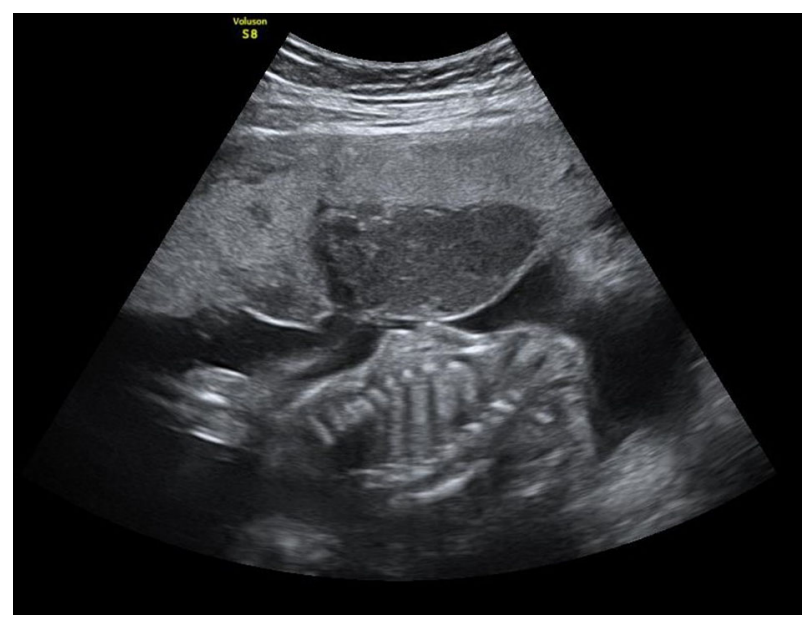

Fig. 1 Chorioangioma at 26 weeks, size 6-5-5 cm

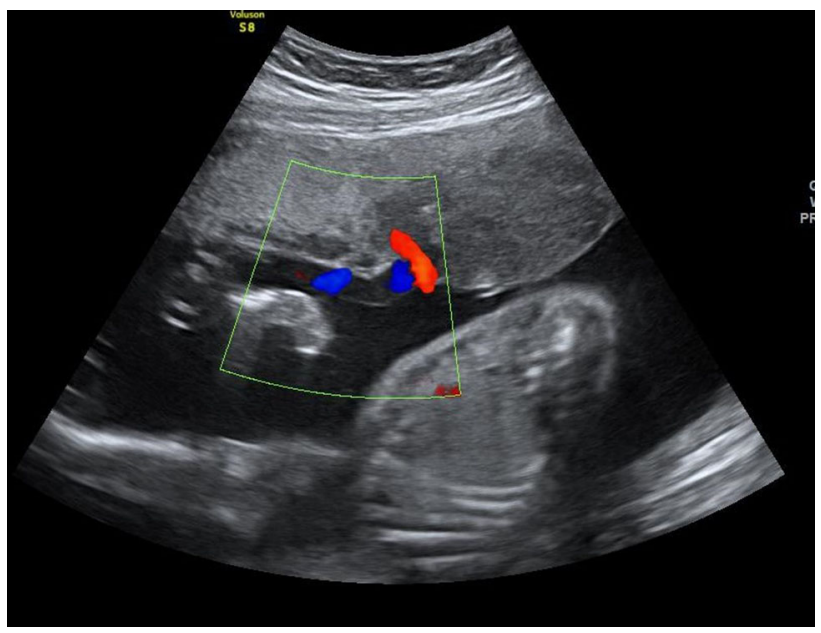

Fig. 2 Chorioangioma at 26 weeks with color doppler

polyhydramnios with an AFI of $24 \mathrm{~cm}$. A single liquor pocket was 10mm deep (Figs. 3, 4, 5).

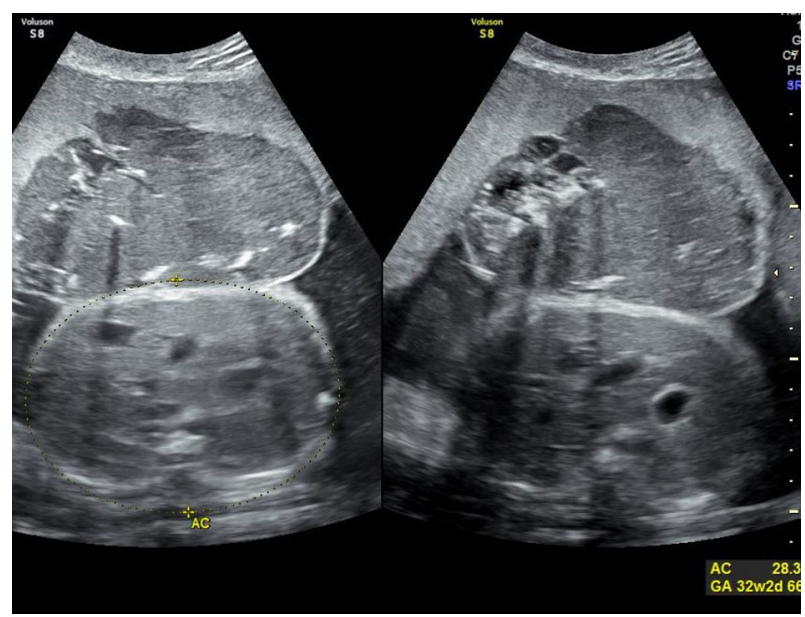

Fig. 3 Chorioangioma at 32 weeks, size $8-9-8 \mathrm{~cm}$ 


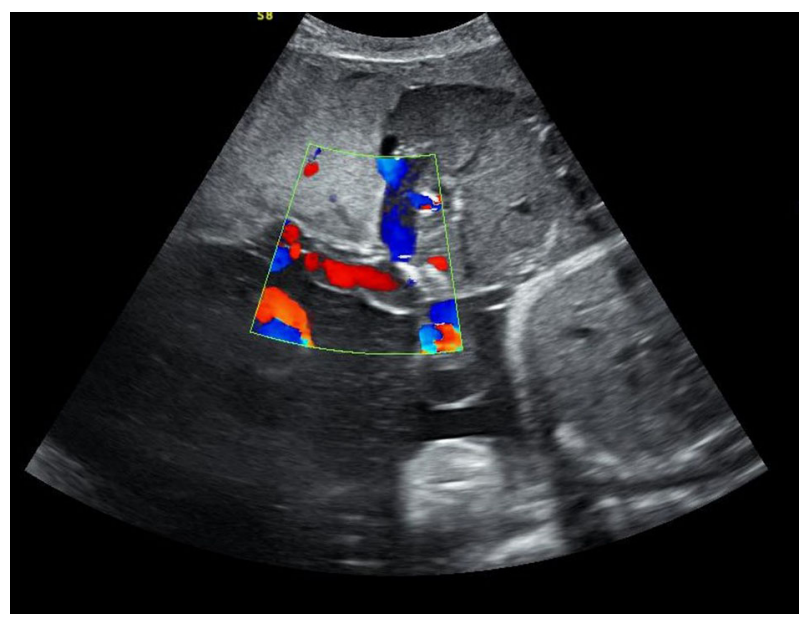

Fig. 4 Chorioangioma at 32 weeks showing tumor near the cord insertion site on color doppler

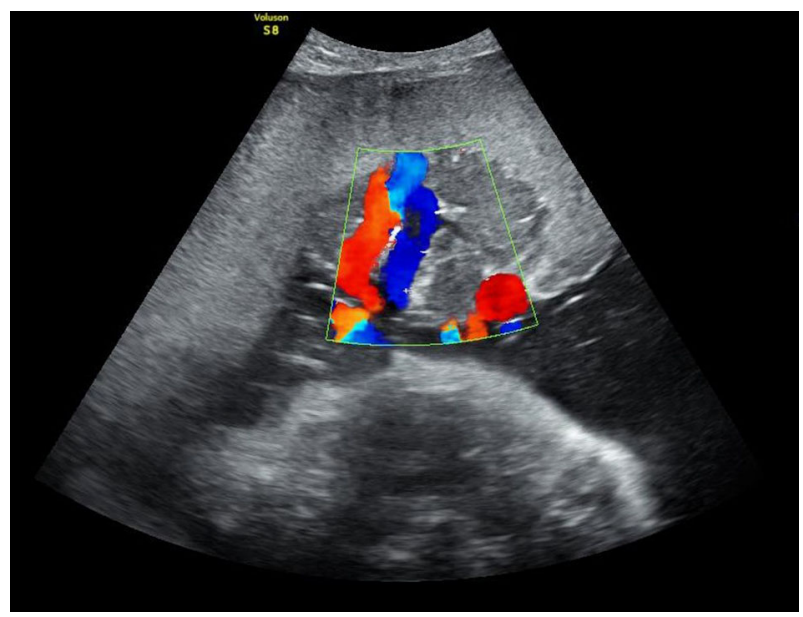

Fig. 5 Chorioangioma with turgid vessels seen on color doppler

Obvious signs of cardiomegaly were seen for which a second opinion was taken. Fetal MCA PSV was reported as normal. The patient was advised to wait for 5-6 days more, with counseling done for possible preterm delivery being planned to avoid fetal cardiac failure and fetal jeopardy. The risk of preterm delivery was explained and steroids were administered. Neonatologists were informed about the case in advance.

The dilemma was to balance the risk of fetal demise versus prematurity. Risks of both, continuation and prolongation of pregnancy were deliberated upon and explained to the couple.

A repeat scan was done after 4 days, and it showed a 34 week fetus, with polyhydramnios and cardiomegaly. The right atrium, left ventricle, and IVC were dilated. Umbilical Doppler was normal. As findings of cardiac failure were seen, patient and relatives were counseled about immediate obstetric intervention.

The decision of preterm lower segment cesarean section (LSCS) was taken for breech presentation. Keeping in mind the possibility of PPH, blood components were kept ready. Informed high risk consent was taken for LSCS. Emergency need for Internal iliac artery ligation, possible hysterectomy were also explained in case of intractable PPH. The need for NICU admission for the neonate had already been explained to the family.

The patient was taken for LSCS under spinal anesthesia. The baby was delivered by the breech, with early clamping of the cord. Watchful expectancy was adopted for the delivery of placenta (no pulling/handling of the placenta). The placenta with the chorioangioma alongside it was expelled spontaneously, (shown in Fig. 6). There was no $\mathrm{PPH}$, and no extension of uterine incision. The LSCS was completed uneventfully. Her post-operative period was also comfortable.

The tumor specimen was sent for histopathological examination, and it confirmed the finding of chorioangioma, with no malignant potential. The mother was stable in the postoperative period, but the neonate had a stormy course.

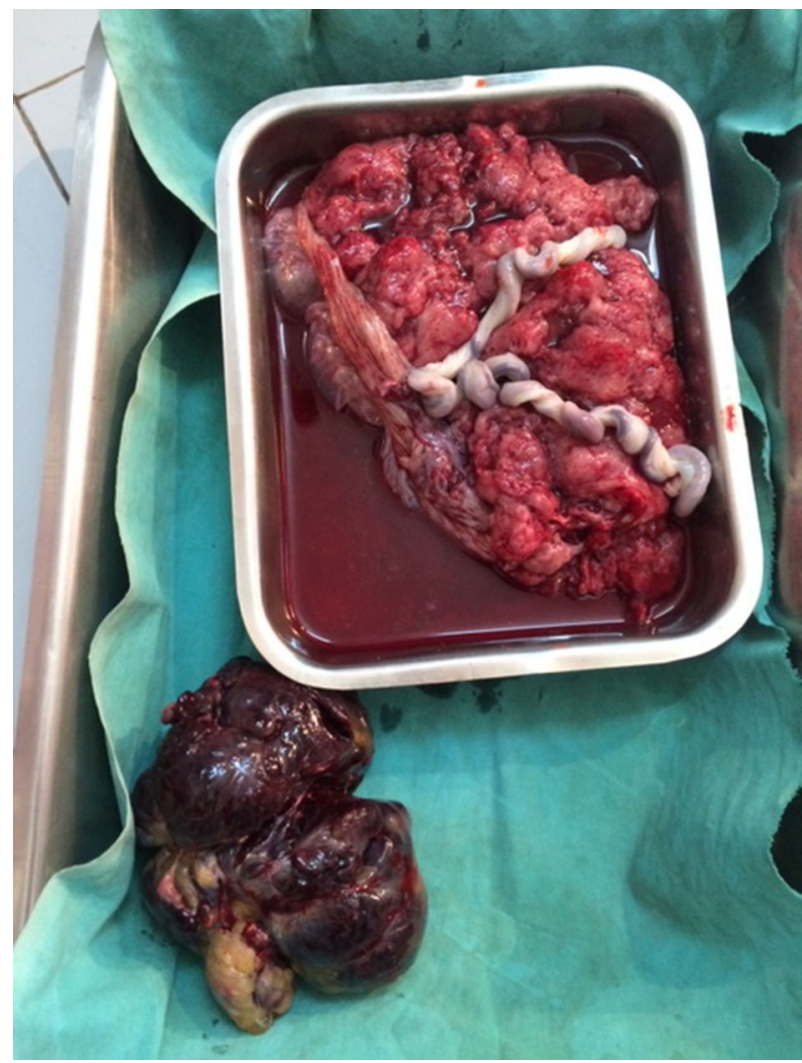

Fig. 6 Placenta with chorioangioma 


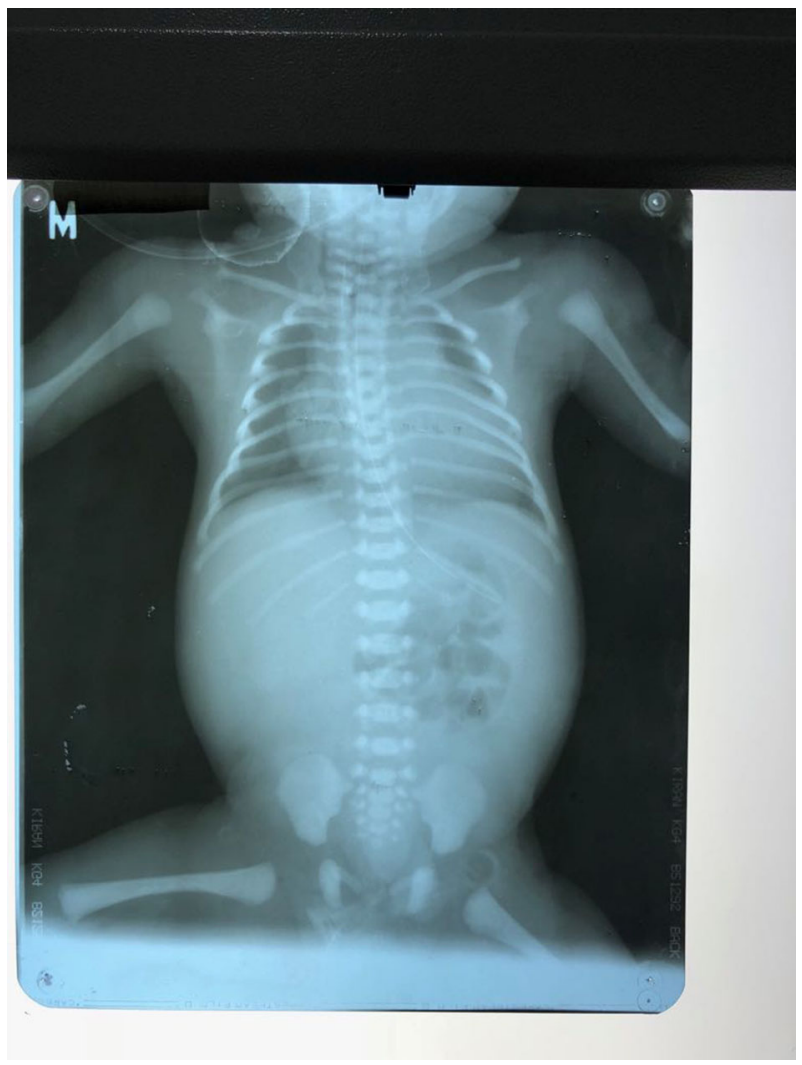

Fig. 7 X-ray of neonate showing cardiomegaly

The neonate went into renal failure secondary to cardiac failure, with DIC. Cardiomegaly was also present as shown in the postnatal chest Xray of the neonate (Fig. 7).

Supportive care in the form of restricted intravenous fluids, inotropes, frusemide and antibiotics were started with respiratory support. For DIC, platelets were administered. Respiratory support was given for 10 days, after which the baby settled down.

Neonatal Echo was done which showed thickened interventricular septum with hypoechoic areas with left ventricular hypertrophy. There was left to right shunt at atrial level and mitral regurgitation, with high right ventricular systolic pressures, suggesting severe pulmonary hypertension. Sildenafil infusion was given and continued for 10 days.

A repeat echo was done on day11, which was within normal limits with decreased pulmonary hypertension and small mitral regurgitation.

Gradually feeds were increased.

The baby settled down in 15 days and was then discharged.

Followup Echocardiography done after 2 months showed a mildly hypertrophic left ventricle.

Initial brain ultrasound showed minimal ventricular dilatation, but later imaging after 3 months was reported as normal.
Regular follow up with a Pediatric cardiologist was kept by the patient. No active medication or intervention was needed after discharge.

A case report is being sent after 1 year, as 1 year followup of the baby has been done, all parameters have been reported as normal. All neuro-behavioral milestones are normal, and cardiac findings also reported as normal.

\section{Discussion}

The ultraound diagnosis of Chorioangioma is based on imaging of a well circumscribed, round, predominantly hypoechoic mass, often near the cord insertion site along the fetal surface of the placenta. They are known to protrude into the amniotic cavity. No definitive etiology or causative reason has been reported.

Giant Chorioangioma ( $>40 \mathrm{~mm}$ in diameter) is a rare placental tumor associated with complications including polyhydramnios, fetal anemia, cardiomegaly, hydrops and increased perinatal mortality [2].

They can be managed conservatively or by therapeutic interventions including direct injection of various chemicals and laser coagulation of the feeding vessels [3, 4].

Injection of toxic substances for the treatment of chorioangioma carries the risk of potential fetal exposure, to which one fetal death has been attributed [3]. Laser photocoagulation can be performed either fetoscopically [4] or using an ultrasound guided interstitial laser coagulation [5]. Fetoscpoy has a reported success of $60-80 \%$, but this may be difficult in cases of anterior placenta $[4,6]$.

In a series by Zanardini [6], the chorioangiomas treated by laser photocoagulation were between 3.5 and $5.4 \mathrm{~cm}$, and close proximity to the cord was considered (as in our case) a contraindication because of fear of excess thermal damage. But Papaioannou et al [7] published a case report of laser photocoagulation of an angioma $14 \mathrm{~cm}$ at widest diameter, near the placental cord insertion.

Hosseinzadeh et al. [8] have also described prenatal therapy for large chorioangiomas.

Even though the present times with technological advances demand advanced options, in a vast country like ours, it may not always be possible. Hence we should have an idea about conservative management, which may be used to have good outcomes without jeopardising maternal and fetal wellbeing $[9,10]$.

We managed our case conservatively because even though the expertise of other imaging and obstetric radiological interventions was available, intervention in chorioangioma had not been attempted by us earlier. The couple and family were counselled and advice of close followup and increased surveillance was given. The patient willingly accepted this. 


\section{Conclusion}

This case signifies the importance of counselling and case documentation.

If intervention is possible, that should be offered to the patient after counselling. Intervention prevents an increase in the size of hyperdynamic circulation and perinatal complications. Intervention if offered, should be done by an expert hand. If that is not possible, then the clinician should decide on conservative management. If the relatives are not willing for intervention, the clinician should be well versed with a conservative approach.

Open Access This article is licensed under a Creative Commons Attribution 4.0 International License, which permits use, sharing, adaptation, distribution and reproduction in any medium or format, as long as you give appropriate credit to the original author(s) and the source, provide a link to the Creative Commons licence, and indicate if changes were made. The images or other third party material in this article are included in the article's Creative Commons licence, unless indicated otherwise in a credit line to the material. If material is not included in the article's Creative Commons licence and your intended use is not permitted by statutory regulation or exceeds the permitted use, you will need to obtain permission directly from the copyright holder. To view a copy of this licence, visit http://creativecommons. org/licenses/by/4.0/.

\section{References}

1. Williams Obstetrics, 23rd edn-chapter 27-Abnormalities of the placenta, umbilical cord and membranes.

2. Ruman U, Chowdhury TS, Nessa M. Placental chorioangioma: a case report. BIRDEM Med J. 2012;2(2):113-5.

3. Callen's ultrasonography in obstetrics and gynecology-sixth edition-chapter 190 ultrasound evaluation of the placenta, membranes and umbilical cord.

4. Wou K, Chen MF, Mallozi A, Brown RN, Shrim A. Pregnancy outcomes with ultrasonographic diagnosis in patients with histologically proven placental chorioangioma. Placenta. 2011;32:671-4.

5. Sepulveda W, Wong AE, Herrera I, Dezerega V. Devoto JC (2009) Endoscopic laser coagulation of feeding vessels in large placental chorioangiomas-report of 3 cases and review of invasive treatment options. Prenat Diagn. 2009;29:201-6.

6. Papaioannou GK, Evangelinakis N, Kourtis P, Monstantinidou A, Papantoniou N. Giant chorioangioma treated with interstitial laser coagulation. Ultrasound Obstet Gynecol. 2018;52(2):280-1.

7. Zanardini C, Papageorghiou A, Bhide A, Thilagnathan B. Giant placental chorioangioma;natural history and pregnancy outcome. Ultrasound Obstet Gynecol. 2010;35:332-6.

8. Hosseinzadeh P, Shamshiraz A, Javadin P, Espinoza J, Gandhi M, Ruano R, Cass D. Prenatal therapy of large placental chorioangioma, case report and review of literature. Am J Perinatal Rep. 2015;5:196-202.

9. Zoppini C, Acacia B. Varying clinical course of large placental chorioangiom. Fetal Diagn Ther. 1997;12:61-4.

10. Acharya S, Pringle S. A case of placental chorioangioma with review of literature. Internet J Gynecol Obstet. 2004;5(1):142.

Publisher's Note Springer Nature remains neutral with regard to jurisdictional claims in published maps and institutional affiliations. 